\title{
Editorial
}

\section{Health-related Behaviors in Pregnancy: A Key to Achieve Better Outcomes}

\author{
Fernanda Garanhani Surita1(1) Daiane Sofia Morais Paulino ${ }^{1(1)}$ Maira Pinho-Pompeu ${ }^{1(1)}$ \\ ${ }^{1}$ Department of Obstetrics and Gynecology, Universidade Estadual de \\ Campinas, Campinas, SP, Brazil
}

Rev Bras Ginecol Obstet 2020;42(3):121-123.

In the last decades, changes in disease patterns from infectious to chronic diseases have made health-related behaviors become critical to the public's health and well-being. ${ }^{1}$ In pregnancy, similarly, the adoption of health-related behaviors has been recognized as a powerful element to minimize the occurrence of adverse maternal and perinatal outcomes and, consequently, improve woman and neonate's health. Moreover, it is well established that the intrauterine environment, which the fetus is exposed to, impacts not only the neonatal outcomes, but also program a susceptibility to long-term metabolic disease development. $^{2}$

Gochman $^{3}$ defined health behavior as "those personal attributes such as beliefs, expectations, motives, values, perceptions, and other cognitive elements; personality characteristics, including affective and emotional states and traits; and overt behavior patterns, actions, and habits that relate to health maintenance, to health restoration, and to health improvement." Besides that, health-related behaviors are part of lifestyle and comprise modifiable health factors. Here, our aim was to discuss health-related behaviors involving diet, physical exercise (PE), healthy weight maintenance, stress management, sleep time, low alcohol intake, and non-smoking in the context of prenatal care.

Studies have shown that maternal dietary behavior modulates epigenetic alterations that impacts on offspring outcomes throughout childhood and can persist into adulthood. Thus, optimizing the nutrition in the first 1,000 days of life is opportune to prevent and reduce the risk of developing chronic diseases in the future. ${ }^{4}$ In this sense, a health pattern of consumption, such as in the Mediterranean diet (rich in fruits, vegetables, lean proteins, whole grains, omega 3 fatty acids and monounsaturated fats), is associated with lower risk of premature birth and newborn small for gestational age (SGA). In contrast, the western dietary pattern, characterized by high consumption of saturated fat, sugar, and salt is correlated with a significant increase in adverse neonatal outcomes. ${ }^{5}$ With regard to maternal health, a healthy dietary pattern was associated with lower risk of gestational diabetes

Address for correspondence Fernanda Garanhani Surita, Department of Obstetrics and Gynecology, Universidade Estadual de Campinas, Campinas, SP, 13083-970, Brazil (e-mail: surita@unicamp.br). mellitus (GDM) ${ }^{6}$ and hypertensive diseases ${ }^{7}$ and was protective against inadequate gestational weight gain (GWG). ${ }^{8}$ According to a dietary guide for the Brazilian population, a healthy eating pattern should be based on the predominant consumption of fresh and minimally processed foods, decreased consumption of processed foods, and avoiding the consumption of ultraprocessed foods. ${ }^{9}$ Thus, guiding an adequate dietary pattern in pregnancy according to the degree of food processing may be a new approach for nutrition care to prevent or minimize the occurrence of unfavorable pregnancy outcomes.

A growing body of evidence shows that the practice of PE during pregnancy reduces the risk of developing GDM, preeclampsia, and hypertensive disorders, in addition to the fact that PE prevents excessive GWG, cesarean section, and postpartum depression. ${ }^{10,11}$ Despite the benefits of PE during pregnancy, it is described that the majority of pregnant women do not engage in any type of PE and tend to decrease the intensity or level of physical activity in the gestational period. ${ }^{12}$ The literature shows that, in Brazil, $20 \%$ of pregnant women ${ }^{12}$ follow the current recommendations for the practice of $\mathrm{PE}$, which propose the weekly accumulation of at least 150 minutes of moderate intensity aerobic physical activity, at least 3 times per week. ${ }^{13}$

The PE and dietary patterns have been recognized as effective interventions for weight maintenance and obesity control. ${ }^{14,15}$ In pregnancy, however, the efforts to maintain a healthy weight are not directed towards weight loss, but towards stimulating adequate GWG. To date, there is no guideline for GWG based on the Brazilian population, and, therefore, the current recommendation follows the guidelines proposed by the Institute of Medicine (IOM), which are formulated as a range for each category of pregestational nutritional status (according to body mass index [BMI]) and according to the gestational period. ${ }^{16}$ However, just monitoring the weight at prenatal care visits is not sufficient to meet the weight gain recommendations. ${ }^{17}$ The preventative measures to avoid inadequate GWG are to instruct pregnant
DOI https://doi.org/ 10.1055/s-0040-1708094. ISSN 0100-7203.
Copyright $\odot 2020$ by Thieme Revinter Publicações Ltda, Rio de Janeiro, Brazil
License terms

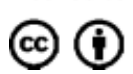


women regarding nutrition, physical activity, and weight gain during prenatal care. ${ }^{18}$ Studies have shown that excessive GWG increases the risk of GDM, hypertensive diseases of pregnancy, cesarean section, postpartum weight retention, obesity, and future metabolic disorders. ${ }^{19,20}$ Besides that, excessive GWG is correlated with macrosomia and childhood adiposity. ${ }^{20,21}$

The maternal psychological state has also been linked with pregnancy outcomes. High maternal stress was associated with increased risk of preterm birth and low birth weight, ${ }^{22}$ chronic immune diseases, obesity, and metabolic disorders. ${ }^{23}$ Furthermore, prenatal maternal stress was associated with the adoption of unhealthy behaviors ${ }^{24}$ and adverse maternal outcomes, such as hypertensive disorders ${ }^{25}$ and postpartum depressive symptoms. ${ }^{26}$ Of note, health practitioners involved in perinatal care should be able to identify maternal distress, even in those women with a subclinical level, and provide appropriate support for women by developing positive coping strategies as well as ensuring that women receive a social support. $^{27}$

In the last decade, the number of studies evaluating the relationship between quality and time of sleep with maternal and perinatal outcomes has grown. Thus, observational studies and systematic reviews have shown that poor sleep quality can predict the duration and type of delivery, ${ }^{28}$ reduce the quality of life and increase the risk of gestational hypertension, GDM, and postpartum depression symptom severity. ${ }^{29-31}$ In addition, sleep duration and sleep quality can affect neonatal outcomes such as birth weight and Apgar scores. ${ }^{32}$ These findings, however, lead us to the need to implement strategies for assessment and monitoring of sleep pattern during prenatal care. The most common methods for assessing sleep quality are actigraphy, polysomnography, and the Pittsburgh Sleep Quality Index (PSQI). Although the latter is a subjective method, it proved to be a good predictor of pregnancy complications. ${ }^{33}$ One of the challenges in improving sleep quality is that sleep quality improvement drugs are often unsafe during pregnancy. ${ }^{34}$ In this sense, effective and safe non-pharmacological strategies for improving sleep quality should be adopted during prenatal care.

The use of psychoactive substances, like alcohol, tobacco, and illicit drugs, in the gestational period is also commonly associated with worse maternal and perinatal outcomes and affect child development. ${ }^{35}$ Thus, aiming to avoid negative consequences, as fetal alcohol spectrum disorders, alcohol intake is discouraged, and, so far, no safe amount of alcohol has been established. Thereby, the current recommendations advocate abstinence among pregnant women and those trying to get pregnant. ${ }^{36}$

Smoking during pregnancy, as well as illicit drugs use, is associated with higher risk of preterm delivery, abortion, intrauterine growth restriction, and premature placental abruption. ${ }^{36}$ Thus, tobacco use is not safe during pregnancy. It is important to highlight that the adverse impacts of tobacco are not limited to active maternal use but also to passive exposure to tobacco. ${ }^{37}$ As part of a positive pregnancy experience, the World Health Organization (WHO) recommends health-care providers explain the dangers of tobacco use (past and present) for the pregnant women and about their exposure to second-hand smoke during every antenatal care visit. Besides that, whenever necessary, pregnant women should be advised and receive psychosocial interventions for tobacco cessation. ${ }^{37}$

Given the above, it is evident that the adoption of healthrelated behaviors during pregnancy is critical for promoting public health. In addition, a multiprofessional team is fundamental for improving the care of pregnant women. Antenatal care should also address the assessment, encouragement, and monitoring of the adoption of health-related behavior to optimize maternal and neonatal outcomes in both short and long term.

\section{Conflict of Interests}

The authors have no conflict of interests to declare.

\section{References}

1 Remington PL, Brownson RC; Centers for Disease Control and Prevention (CDC). Fifty years of progress in chronic disease epidemiology and control. MMWR Suppl. 2011;60(04):70-77

2 Eriksson JG. Early programming of later health and disease: factors acting during prenatal life might have lifelong consequences. Diabetes. 2010;59(10):2349-2350. Doi: 10.2337/db10-0878

3 Gochman DS. Labels, systems and motives: some perspectives for future research and programs. Health Educ Q. 1982;9(23):263-270. Doi: 10.1177/109019818200900213

4 Spencer SJ. Early life programming of obesity: the impact of the perinatal environment on the development of obesity and metabolic dysfunction in the offspring. Curr Diabetes Rev. 2012;8(01): 55-68. Doi: 10.2174/157339912798829214

5 Chen X, Zhao D, Mao X, Xia Y, Baker PN, Zhang H. Maternal dietary patterns and pregnancy outcome. Nutrients. 2016;8(06):E351. Doi: $10.3390 /$ nu8060351

6 Tryggvadottir EA, Medek H, Birgisdottir BE, Geirsson RT, Gunnarsdottir I. Association between healthy maternal dietary pattern and risk for gestational diabetes mellitus. Eur J Clin Nutr. 2016;70(02):237-242. Doi: 10.1038/ejcn.2015.145

7 Agrawal S, Fledderjohann J, Vellakkal S, Stuckler D. Adequately diversified dietary intake and iron and folic acid supplementation during pregnancy is associated with reduced occurrence of symptoms suggestive of pre-eclampsia or eclampsia in Indian women. PLoS One. 2015;10(03):e0119120. Doi: 10.1371/journal. pone.0119120

8 Ancira-Moreno M, Vadillo-Ortega F, Rivera-Dommarco JA, Sánchez BN, Pasteris J, Batis C, et al. Gestational weight gain trajectories over pregnancy and their association with maternal diet quality: Results from the PRINCESA cohort. Nutrition. 2019; 65:158-166. Doi: 10.1016/j.nut.2019.02.002

9 Ministério da Saúde. Secretaria de Atenção à Sáude. Departamento de Atenção Básica [Internet]. Guia alimentar para a população brasileira. 2nd ed. Brasília (DF): Ministério da Saúde; 2014 [cited 2019 Aug 10]. Available from: http://bvsms.saude.gov.br/bvs/publicacoes/guia_alimentar_populacao_brasileira_2ed.pdf

10 Davenport MH, Ruchat SM, Poitras VJ, Jaramillo Garcia A, Gray CE, Barrowman $\mathrm{N}$, et al. Prenatal exercise for the prevention of gestational diabetes mellitus and hypertensive disorders of pregnancy: a systematic review and meta-analysis. Br J Sports Med. 2018;52(21):1367-1375. Doi: 10.1136/bjsports-2018-099355

11 Poyatos-León R, García-Hermoso A, Sanabria-Martínez G, Álvarez-Bueno C, Cavero-Redondo I, Martínez-Vizcaíno V. Effects of exercise-based interventions on postpartum depression: A meta-analysis of randomized controlled trials. Birth. 2017;44 (03):200-208. Doi: 10.1111/birt.12294 
12 Nascimento SL, Surita FG, Godoy AC, Kasawara KT, Morais SS. Physical activity patterns and factors related to exercise during pregnancy: a cross sectional study. PLoS One. 2015;10(06): e0128953. Doi: 10.1371/journal.pone.0128953

13 Mottola MF, Davenport MH, Ruchat SM, Davies GA, Poitras VJ, Gray CE, et al. 2019 Canadian guideline for physical activity throughout pregnancy. BrJ Sports Med. 2018;52(21):1339-1346. Doi: 10.1136/ bjsports-2018-100056

14 Swift DL, McGee JE, Earnest CP, Carlisle E, Nygard M, Johannsen NM. The effects of exercise and physical activity on weight loss and maintenance. Prog Cardiovasc Dis. 2018;61(02):206-213. Doi: $10.1016 /$ j.pcad.2018.07.014

15 Popkin BM, Adair LS, Ng SW. Global nutrition transition and the pandemic of obesity in developing countries. Nutr Rev. 2012;70 (01):3-21. Doi: 10.1111/j.1753-4887.2011.00456.x

16 Rasmussen KM, Yaktine AL, Eds. Committee to Reexamine IOM Pregnancy Weight Guidelines, Food and Nutrition Board and Board on Children, Youth, and Families. Weight gain during pregnancy: reexamining the guidelines. Washington (DC): National Academies Press; 2009

17 Fealy SM, Taylor RM, Foureur M, Attia J, Ebert L, Bisquera A, Hure AJ. Weighing as a stand-alone intervention does not reduce excessive gestational weight gain compared to routine antenatal care: a systematic review and meta-analysis of randomised controlled trials. BMC Pregnancy Childbirth. 2017;17(01):36. Doi: 10.1186/s12884-016-1207-2

18 Muktabhant B, Lawrie TA, Lumbiganon P, Laopaiboon M. Diet or exercise, or both, for preventing excessive weight gain in pregnancy. Cochrane Database Syst Rev. 2015; ((06):CD007145. Doi: 10.1002/14651858.CD007145.pub3

19 McDowell M, Cain MA, Brumley J. Excessive gestational weight gain. J Midwifery Womens Health. 2019;64(01):46-54. Doi: 10.1111/jmwh.12927

20 Kominiarek MA, Peaceman AM. Gestational weight gain. Am J Obstet Gynecol. 2017;217(06):642-651. Doi: 10.1016/j.ajog.2017.05.040

21 Goldstein RF, Abell SK, Ranasinha S, et al. Gestational weight gain across continents and ethnicity: systematic review and metaanalysis of maternal and infant outcomes in more than one million women. BMC Med. 2018;16(01):153. Doi: 10.1186/s12916-0181128-1

22 Staneva A, Bogossian F, Pritchard M, Wittkowski A. The effects of maternal depression, anxiety, and perceived stress during pregnancy on preterm birth: A systematic review. Women Birth. 2015; 28(03):179-193. Doi: 10.1016/j.wombi.2015.02.003

23 Cao-Lei L, de Rooij SR, King S, Matthews SG, Metz GAS, Roseboom TJ, Szyf M. Prenatal stress and epigenetics. Neurosci Biobehav Rev. 2017:S0149-7634(16)30726-6

24 Lobel M, Cannella DL, Graham JE, DeVincent C, Schneider J, Meyer BA. Pregnancy-specific stress, prenatal health behaviors, and birth outcomes. Health Psychol. 2008;27(05):604-615. Doi: 10.1037/a0013242
25 Leeners B, Neumaier-Wagner P, Kuse S, Stiller R, Rath W. Emotional stress and the risk to develop hypertensive diseases in pregnancy. Hypertens Pregnancy. 2007;26(02):211-226. Doi: 10.1080/10641950701274870

26 Nierop A, Bratsikas A, Zimmermann R, Ehlert U. Are stressinduced cortisol changes during pregnancy associated with postpartum depressive symptoms? Psychosom Med. 2006;68(06): 931-937. Doi: 10.1097/01.psy.0000244385.93141.3b

27 Goletzke J, Kocalevent RD, Hansen G, Rose M, Becher H, Hecher K, et al Prenatal stress perception and coping strategies: Insights from a longitudinal prospective pregnancy cohort. J Psychosom Res. 2017;102:8-14. Doi: 10.1016/j.jpsychores.2017.09.002

28 Naghi I, Keypour F, Ahari SB, Tavalai SA, Khak M. Sleep disturbance in late pregnancy and type and duration of labour. J Obstet Gynaecol. 2011;31(06):489-491. Doi: 10.3109/01443615.2011.579196

29 Sut HK, Asci O, Topac N. Sleep quality and health-related quality of life in pregnancy. J Perinat Neonatal Nurs. 2016;34(04):302-309. Doi: $10.1097 / J P N .0000000000000181$

30 Facco FL, Grobman WA, Reid KJ, Parker CB, Hunter SM, Silver RM, et al. Objectively measured short sleep duration and later sleep midpoint in pregnancy are associated with a higher risk of gestational diabetes. Am J Obstet Gynecol. 2017;217(04):447. e1-447.e13. Doi: 10.1016/j.ajog.2017.05.066

31 Park EM, Meltzer-Brody S, Stickgold R. Poor sleep maintenance and subjective sleep quality are associated with postpartum maternal depression symptom severity. Arch Women Ment Health. 2013;16(06):539-547. Doi: 10.1007/s00737-013-0356-9

32 Zafarghandi N, Hadavand S, Davati A, Mohseni SM, Kimiaiimoghadam F, Torkestani F. The effects of sleep quality and duration in late pregnancy on labor and fetal outcome. J Matern Fetal Neonatal Med. 2012;25(05):535-537. Doi: 10.3109/14767058.2011.600370

33 Volkovich E, Tikotzky L, Manber R. Objective and subjective sleep during pregnancy: links with depressive and anxiety symptoms. Arch Women Ment Health. 2016;19(01):173-181. Doi: 10.1007/ s00737-015-0554-8

34 Takzare N, Hosseini MJ, Bakhtiarian A, Takzare A, Habibi P. The teratogenic effects of flurazepam intake during organogenesis of the rat fetus. Toxicol Mech Methods. 2008;18(09):711-716. Doi: 10.1080/15376510801897739

35 Pereira CM, Pacagnella RC, Parpinelli MA, Andreucci CB, Zanardi $\mathrm{DM}$, Souza R, et al. Drug use during pregnancy and its consequences: a nested case control study on severe maternal morbidity. Rev Bras Ginecol Obstet. 2018;40(09):518-526. Doi: 10.1055/ s-0038-1667291

36 Federação Brasileira das Associações de Ginecologia e Obstetrícia. Manual de assistência pré-natal [Internet]. 2a ed. São PauloFEBRASG02014 [cited 2019 Apr 12]. Available from: https://www. febrasgo.org.br/images/arquivos/manuais/Manuais_Novos/Manual _Pre_natal_25SET.pdf

37 World Health Organization. WHO recommendations on antenatal care for a positive pregnancy experience. Geneva: WHO; 2016 